\title{
Promoção e vigilância da saúde no contexto da regionalização da assistência à saúde no SUS
}

\author{
Health promotion and surveillance \\ in the context of health care regionalization \\ in the Unified National Health System in Brazil
}

Carmen Fontes Teixeira 1

\footnotetext{
1 Instituto de Saúde Coletiva, Universidade Federal da Bahia. Rua Padre Feijó 29, Salvador, $B A$ 40110-170, Brasil. carment@ufba.br
}

\begin{abstract}
This article discusses the limits and possibilities in the implementation of health promotion and surveillance measures, in light of the regionalization proposal contained in the Health Care Operational Norm (NOAS) adopted by the Brazilian Ministry of Health in 2001. The proposal is characterized as an opportunity to move forward in the establishment of micro-regional systems guaranteeing integral health care, in keeping with the operational capacity of the Unified National Health System in each Region and State of the country. The article goes on to analyze the contribution of various proposals for change in health practices for the development of health promotion, prevention of risks and diseases, and reorientation of individual and collective care as they are incorporated into the NOAS implementation process in various States of the country.
\end{abstract}

Key words Health Policy; Health Promotion; Health Surveillance; Health Care

Resumo O presente trabalho discute os limites e possibilidades de implementação de práticas de promoção e vigilância da saúde, levando em conta a proposta de regionalização contida na Norma Operacional da Assistência à Saúde (NOAS), adotada pelo Ministério de Saúde em 2001. Caracteriza essa proposta como uma oportunidade para se avançar na construção de sistemas microrregionais que garantam a integralidade da atenção à saúde, de acordo com a capacidade operacional do Sistema Único de Saúde em cada região e Estado do país. Em seguida analisa a contribuição das diversas propostas de mudança nas práticas de saúde para o desenvolvimento da promoção, prevenção de riscos e agravos, e reorientação da assistência individual e coletiva, na medida em que venham a ser incorporadas ao processo de implementação da NOAS nos diversos Estados da Federação.

Palavras-chave Política de Saúde; Promoção da Saúde; Vigilância à Saúde; Assistência à Saúde 


\section{Introdução}

O debate acerca do processo, resultados e perspectivas da reforma do sistema de saúde brasileiro é sempre necessário e, sem dúvida, extremamente oportuno no momento atual, em que se apresenta uma proposta de mudança na estratégia de descentralização e regionalização dos serviços.

Tendo em vista a busca de alternativas de ação que possam contribuir para o alcance ou a aproximação dos objetivos de universalização, integralidade e eqüidade, é importante que se amplie a investigação e a reflexão crítica acerca do processo e dos resultados decorrentes da implementação de inovações gerenciais, organizativas e operacionais no âmbito de sistemas locais de saúde que vem ocorrendo ao longo dos últimos anos.

Segundo o desenvolvimento de experiências de formação de pessoal e atividades de cooperação técnica com Secretarias Estaduais (SES) e Municipais de Saúde (SMS), venho refletindo sobre a possibilidade de construção de modelos de atenção à saúde da população que levem em conta a heterogeneidade das condições de vida dos diversos grupos sociais, bem como a diversidade de situações existentes nas diversas regiões, estados e municípios brasileiros com respeito à organização e gestão do Sistema Único de Saúde (SUS).

Este texto é, portanto, uma tentativa de atualizar e sistematizar um conjunto de idéias e propostas acerca do processo de descentralização no âmbito do SUS, e seus possíveis desdobramentos do ponto de vista da reorganização das práticas de saúde em nível local. Considerando a especificidade do processo de descentralização e reorganização dos serviços no contexto da reforma do sistema de saúde brasileiro, o foco desta reflexão tem oscilado de acordo com as variadas acepções que o termo "local" adquiriu ao longo dos últimos anos, seja enquanto "distrito sanitário", nos primórdios do processo de reforma do setor (1988-1993), seja enquanto "sistema municipal de saúde", no período subseqüente, onde se enfatizou a municipalização (1993-2000) e, mais recentemente, "microrregião de saúde", conforme a mais nova proposta governamental de "regionalização da assistência à saúde” (NOAS 2001).

Desse modo, o objetivo do texto é discutir os limites e perspectivas de implementação de políticas públicas e práticas de promoção e vigilância da saúde no âmbito de sistemas locais, levando em conta o processo de regionalização da assistência à saúde, desencadeado no âmbito do SUS brasileiro em 2001. Tomo como pon- to de partida uma breve revisão acerca do processo de descentralização e do debate sobre diversas propostas de construção de "modelos assistenciais" alternativos ao modelo vigente, chamando a atenção para a necessidade de se distinguir, no conjunto de propostas políticas e estratégias que vêm sendo apresentadas com vistas à introdução de mudanças no sistema de saúde, aquelas que dizem respeito, especificamente, a mudanças na forma de organização das práticas de saúde (Silva Jr., 1998). Em seguida, pretendo identificar os desafios que se colocam na conjuntura atual para que o processo de redefinição das políticas de atenção à saúde e reorganização dos serviços em nível local leve em conta, não apenas a necessidade de se garantir a integralidade do cuidado, senão que, a eqüidade na distribuição social das ações e serviços.

\section{A descentralização da gestão do SUS: equilíbrio instável}

O processo de reorientação da gestão do SUS, desenvolvido ao longo dos últimos dez anos, pode ser caracterizado como um movimento pendular de descentralização/centralização, pontuado pela elaboração e implementação das Normas Operacionais Básicas. O movimento descentralizador foi iniciado com a implementação das Normas Operacionais Básicas de 1993 (NOB 01/93) (MS, 1993) e especialmente a de 1996 (NOB 01/96) (MS, 1996), que induziram a redefinição de funções e competências das três esferas de governo (federal, estadual e municipal) no que se refere à gestão, organização e prestação de serviços de saúde, através da transferência de recursos (financeiros, basicamente, mas também físicos, humanos e materiais) do nível federal e estadual para os municípios.

Nesse contexto, um processo de (re)centralização estaria se iniciando no momento atual, com a implementação da Norma Operacional da Assistência à Saúde (NOAS 2001) (MS, 2001), que pretende estimular um fortalecimento do papel das Secretarias Estaduais de Saúde, no sentido de assumirem a coordenação de um processo de regionalização da assistência que implica na organização de sistemas microrregionais de saúde, com os quais se busca superar uma "excessiva” descentralização da gestão ocorrida no momento anterior.

De fato, pode-se interpretar este movimento de vários ângulos. Do ponto de vista político-institucional, o processo de elaboração e implementação das Normas Operacionais corres- 
ponde, de certa forma, a mudanças na correlação de forças entre grupos municipalistas mais "radicais" e grupos que defendem um "federalismo" na reestruturação da distribuição de poder no processo de construção do sistema, o que implica o debate permanente acerca da intensidade e da forma de redefinição de funções e competências entre as três esferas de governo.

Uma análise mais detalhada do processo de formulação e implementação das NOBs 01/93 e 01/96 poderia revelar, seguramente, o predomínio da vertente "municipalista" na concepção acerca da distribuição do poder e dos mecanismos de descentralização dos recursos para os estados e municípios (Levcovitz et al., 2001). O processo de operacionalização em si, entretanto, permaneceu sob controle das instâncias de gestão centralizadas, tanto no âmbito do Ministério da Saúde (MS), quanto nas Secretarias de Estado, o que explica, inclusive, a heterogeneidade de ritmos de implantação das NOBs nos vários estados do país, de acordo com a disposição mais ou menos "municipalista" dos governos estaduais (Molesini, 1999). Já a NOAS 2001 parece resultar da conquista de uma vertente "federalista", que defende o fortalecimento do papel das SES no sentido de coordenar um processo de organização de sistemas microrregionais de saúde, agregando pequenos municípios em torno de municípios "pólos”, os quais devem ter condições de assumir a Gestão Plena do sistema municipal.

Isso se expressa, do ponto de vista econômico-financeiro, no debate sobre os mecanismos jurídico-políticos e institucionais que operacionalizam o processo de transferência de recursos entre o nível federal e as instâncias estaduais e municipais, mas, principalmente, se materializa no debate em torno das responsabilidades de cada nível com relação ao custeio das ações e serviços de saúde nos vários níveis de complexidade. Diversamente da NOB 01/96, que estimulou uma certa competição entre os municípios, na medida em que estabeleceu incentivos financeiros ao aumento da produtividade e ampliação de responsabilidades sobre a produção de serviços, a NOAS 2001 enfatiza a cooperação e recupera a noção de economia de escala como fundamento para a racionalização (e a reconcentração) de recursos, especialmente aqueles destinados aos investimentos em serviços de média e alta complexidade, realizados nos municípios "pólos" de microrregiões de saúde.

Finalmente, do ponto de vista técnico-assistencial, a NOAS resgata a possibilidade de se construir sistemas de serviços de saúde que, ultrapassando os limites territoriais dos muni- cípios (levando em conta que a maioria é de pequeno porte), alcancem a integralidade do cuidado (integralidade relativa à capacidade instalada em cada microrregião). Para isso, assume uma lógica organizacional e programática cujo elemento de referência é o grau de complexidade tecnológica dos serviços existentes nos diversos municípios, propondo uma delimitação territorial correspondente ao estabelecimento de dois níveis de atenção: a "atenção básica ampliada”, organizada no espaço de um módulo assistencial e a "atenção integral à saúde", que constitui o conjunto de módulos assistenciais integrados em uma microrregião de saúde.

Segundo a NOAS 2001, a resolutividade de um módulo assistencial correspondente ao primeiro nível de referência, que inclui a existência de serviços de laboratório, radiologia simples, unidade de saúde obstétrica, psicologia, fisioterapia, ações de odontologia especializada, leitos hospitalares nas especialidades básicas. Nesse sentido, um módulo assistencial pode corresponder a apenas um município ou incluir vários outros de pequeno porte, cuja capacidade instalada tomada em conjunto corresponda ao nível de resolutividade definida na NOAS 2001. Um módulo assistencial responde, portanto, pela atenção básica e pela atenção "mínima da média complexidade" no município ou no conjunto dos municípios que compõem o módulo. A delimitação dos módulos assistenciais contempla a identificação do ou dos municípios que o compõem, caso em que se determina o município "sede" do módulo. A microrregião de saúde, por sua vez, conta, além da atenção básica prestada nos diversos módulos assistências que a compõem, com a atenção de média e alta complexidade oferecida por serviços que se concentram, em geral, no município "pólo" da microrregião (NOAS 2001).

A questão que se coloca, entretanto, diz respeito aos limites da "integralidade" concebida enquanto "integralidade da assistência à saúde", na perspectiva do cuidado médico, individual, curativo. Em outras palavras, diz respeito a uma concepção de "integralidade" restrita à racionalização da oferta de serviços voltados ao atendimento à demanda espontânea, o que significa a criação de condições mais "favoráveis” à reprodução do modelo médico assistencial privatista, hegemônico e do modelo sanitarista ainda vigentes no âmbito do SUS. O modelo médico-assistencial privatista é "centrado no atendimento de doentes (demanda espontânea ou induzida pela oferta), com ênfase na assistência ambulatorial e hospitalar de alto custo, prestada principalmente pela rede con- 
tratada e conveniada com o SUS, apresentando sérios limites para uma atenção comprometida com a efetividade, eqüidade e necessidades de saúde, ainda que possa proporcionar uma assistência de qualidade em algumas situações" (Lucchese et al., 2000). Já o "modelo sanitarista", voltado para o enfrentamento de problemas de saúde selecionados e para o atendimento de necessidades específicas de determinados grupos, através de ações de caráter coletivo (campanhas sanitárias, programas especiais, ações de vigilância epidemiológica e sanitária) tem evidentes limitações quando se trata de atender as demandas da população por uma atenção integral, com qualidade, efetividade e eqüidade (Lucchese et al., 2000).

Desse modo, cabe problematizar a proposta de "regionalização da assistência", chamando a atenção para a necessidade de se rever e aprofundar o debate sobre as propostas alternativas que vêm sendo elaboradas e experimentadas, no sentido de construir "modelo(s)" fundado(s) em uma concepção que não se limite à garantia da assistência e se refira à integralidade da atenção à saúde, levando-se em conta a heterogeneidade das condições de vida e da situação epidemiológica dos diversos grupos da população nas várias regiões e estados do país.

Nesse sentido, creio que muito se tem avançado nos últimos anos, ao menos no âmbito acadêmico, ainda que o impacto desse debate e das experiências que vêm suscitando, não tenha impregnado, suficientemente ao meu ver, o discurso político e, principalmente, a prática governamental. Sem dúvida, a retórica da "mudança do modelo assistencial" faz hoje parte das propostas de política de saúde, especialmente a partir da redefinição dos programas de saúde da família (PACS/PSF), porém, não se conta com evidências de que isso estaria de fato acontecendo. Até o momento, parece que o PSF não tem tido poder de induzir mudanças significativas na organização do conjunto da rede, a ponto de assegurar à sua clientela acesso aos níveis de maior complexidade, nem parece caminhar para a universalização da cobertura, mesmo de ações básicas (MS, 2000).

Caberia, portanto, aproveitar-se a oportunidade colocada pelo processo de implementação da NOAS 2001 nos diversos estados, para a renovação e intensificação do debate em torno das propostas e estratégias de mudança e transformação das práticas de atenção à saúde, de modo que a criação dos "módulos assistenciais" e "sistemas microrregionais de saúde" venha incorporar e articular práticas de promoção da saúde e prevenção de riscos e agravos, bem como a reorientação da assistência individual e coletiva. Para isso, é necessário revisar as propostas existentes e estabelecer mecanismos de difusão e cooperação interinstitucional, que contribuam para o estreitamento das relações entre os centros acadêmicos e organismos governamentais nos diversos níveis, especialmente no âmbito estadual e municipal.

\section{A transformação do modelo de atenção à saúde: intenção e gesto}

Em um texto recentemente produzido como subsídio aos debates na 11ạ Conferência Nacional de Saúde, tratamos de enfatizar a definição de "modelos assistenciais" elaborada por Paim (1993, 1999, comunicação pessoal), segundo a qual estes podem ser entendidos como "combinações de saberes (conhecimentos) $e$ técnicas (métodos e instrumentos) utilizadas para resolver problemas e atender necessidades de saúde individuais e coletivas. Nesse sentido, um modelo de atenção não é, simplesmente uma forma de organização dos serviços de saúde nem tampouco um modo de administrar (gerir ou gerenciar) um sistema de saúde. Os modelos de atenção à saúde são formas de organização das relações entre sujeitos (profissionais de saúde e usuários) mediadas por tecnologias (materiais e não materiais), utilizadas no processo de trabalho em saúde, cujo propósito é intervir sobre problemas (danos e riscos) e necessidades sociais de saúde historicamente definidas" (Teixeira, 2000:261-262).

Pode-se até conceber a existência de uma concepção "ampliada", sistêmica, sobre "modelo de atenção", que inclui três dimensões: uma dimensão gerencial, relativa aos mecanismos de condução do processo de reorganização das ações e serviços; uma organizativa, que diz respeito ao estabelecimento das relações entre as unidades de prestação de serviços, geralmente levando em conta a hierarquização dos níveis de complexidade tecnológica do processo de produção do cuidado, e a dimensão propriamente técnico-assistencial, ou operativa, que diz respeito às relações estabelecidas entre o(s) sujeito(s) das práticas e seus objetos de trabalho, relações estas mediadas pelo saber e tecnologia que operam no processo de trabalho em saúde, em vários planos (promoção da saúde, prevenção de riscos e agravos, e recuperação e reabilitação).

Nessa perspectiva "ampliada", uma transformação do modelo de atenção para ser concretizada, exige a conjunção de propostas e estratégias sinérgicas nas três dimensões. Mudanças parciais, entretanto, podem acontecer em 
cada uma das dimensões assinaladas, constituindo processos que podem facilitar transformações mais amplas. Assim, propostas de mudança no processo político-gerencial, com a introdução, por exemplo, de tecnologias de gestão que proporcionem a identificação de problemas e necessidades de saúde em uma perspectiva social e epidemiologicamente orientada, podem favorecer a ocorrência de mudanças nas práticas de saúde propriamente ditas, por induzir ao privilegiamento de ações voltadas à intervenção sobre os determinantes dos problemas e não apenas aos seus efeitos (Teixeira, 2001). Na mesma linha, a introdução de mecanismos de controle e avaliação do processo de prestação de serviços, principalmente sobre a rede privada contratada e conveniada com o sistema público, é de fundamental importância para o estabelecimento de uma adequação entre a oferta e as necessidades e problemas de saúde da população, contribuindo para a correção dos efeitos mais perversos da lógica de mercado no setor (Solla \& Menezes, 2000).

Do mesmo modo, a introdução de mudanças na dimensão organizativa, quer seja pela modificação nas proporções entre os diversos níveis de organização da produção dos serviços, quer seja pelo estabelecimento de relações hierárquicas entre unidades de produção de serviços nos níveis de complexidade (referência e contra-referência) tecnológica, ainda que sejam fundamentalmente estratégias de racionalização de custos, podem contribuir para a indução de práticas mais adequadas aos problemas e necessidades de saúde. Nessa perspectiva, colocam-se, por exemplo, as propostas de ampliação da "rede básica" de serviços de saúde, cuja expansão, em última instância pode alterar a proporção estabelecida entre "cuidados primários", "secundários e terciários", ou usando a terminologia da NOAS, entre a "rede básica" e a "atenção de média e alta complexidade".

$\mathrm{Na}$ mesma linha, as propostas dirigidas ao estabelecimento de um pacto de responsabilidades entre vários municípios, que podem vir a compor, em conjunto, uma microrregião de saúde, implicam, em última análise, na criação de possibilidades de acesso a uma gama variada de ações e serviços que, de outro modo, não poderiam ser garantidos à população, principalmente aquela que habita os municípios menores, onde se constata mais insuficiências de infra-estrutura do sistema.

Tudo isso é necessário, porém não suficiente para a transformação propriamente dita do modelo de atenção. Esta exige a implementação de mudanças no processo de trabalho em saúde, tanto no que se refere a seus propósitos ou finalidades, quanto nos seus elementos estruturais, isto é, no objeto de trabalho, nos meios de trabalho, no perfil dos sujeitos e principalmente, nas relações estabelecidas entre eles e a população usuária dos serviços.

Do ponto de vista das finalidades ou propósitos da atenção à saúde, trata-se de superar o modelo centrado na atenção à "demanda espontânea”, de atendimento a doentes, para incluir ações de prevenção de riscos e agravos e de promoção da saúde para além dos muros das unidades, isto é, nos territórios onde vive e trabalha a população da área de abrangência dos serviços, sejam estes delimitados enquanto "área de abrangência" de unidades de saúde, seja, como prevê a NOAS, o espaço compreendido em um "módulo assistencial" e, principalmente, o espaço circunscrito de uma microrregião de saúde.

A ênfase do processo de prestação de serviços se desloca do eixo "recuperar a saúde de indivíduos doentes" para: "prevenir riscos e agravos" e "promover a saúde das pessoas e dos grupos populacionais", o que implica tomar como objeto os problemas de saúde e seus determinantes, organizando-se a atenção de modo a incluir não apenas as ações e serviços que incidem sobre os "efeitos" dos problemas (doença, incapacidade e morte), mas, sobretudo, as ações e serviços que incidem sobre as "causas" (condições de vida, trabalho e lazer), ou seja, no modo de vida das pessoas e dos diversos grupos sociais (Paim, 1994; Teixeira et al., 1998).

A redefinição do objeto de trabalho exige a utilização de saberes e tecnologias consentâneas com a ampliação e diversificação do leque de ações e serviços, o que, por sua vez, se reflete na necessidade de mudança no perfil dos sujeitos do processo de trabalho, tanto no plano individual, de cada profissional e trabalhador de saúde, quanto, principalmente, no perfil do "sujeito coletivo". Entenda-se por "sujeito coletivo", não apenas a equipe multiprofissional responsável pelas ações de saúde em cada território específico, como se coloca no âmbito da estratégia de Saúde da Família, em que pesem seus limites (Campos \& Belisário, 2001; Paim, 2001), mas a população organizada em torno da promoção da saúde e da melhoria da qualidade de vida, em um processo de "apoderamento” não só político, mas também cultural.

A introdução de mudanças nas finalidades, no objeto e no sujeito do processo de trabalho em saúde incidem, em seu conjunto, sobre as relações estabelecidas e os saberes e tecnologias que utilizam para a apreensão do(s) objeto(s), entre os sujeitos, profissionais e trabalhadores de saúde, e a população usuária do siste- 
ma de serviços. Cabe ressaltar que essas relações sociais têm uma dimensão técnica, mas também uma dimensão ética, política e cultural, que circunscreve a primeira, embora na maioria das vezes sua relevância escape à percepção dos sujeitos envolvidos, até pela hipervalorização da dimensão tecnológica nas práticas de saúde no mundo contemporâneo.

A transformação do modelo de atenção à saúde, pelo exposto, é um processo complexo e para o seu desenvolvimento, como diria Mendes (1994), é necessário não apenas clareza estratégica e paciência histórica, mas sobretudo, competência política, técnica e administrativa. Muito dessa competência já vem sendo acumulada, seja no âmbito político-institucional, especialmente em nível municipal, seja no âmbito acadêmico; em vários centros de pesquisa, formação de pessoal e cooperação técnica na área de Saúde Coletiva.

\section{Construindo alternativas: um processo de múltiplas faces}

Com base na revisão e sistematização da experiência acumulada é possível elencar um conjunto de propostas, que podem ser acionadas pelos gestores e técnicos responsáveis pela implementação das novas diretrizes de organização dos serviços contidas na NOAS e em outros documentos de política no contexto atual.

Nesse sentido, cabe resgatar as lições emanadas de experiências inovadoras em dezenas de municípios brasileiros, que vêm tentando implementar ações intersetoriais de promoção da saúde, atividades de educação e comunicação social voltadas para o fortalecimento da consciência acerca dos direitos sanitários e formas de proteção da saúde e prevenção de riscos, bem como os esforços de reorganização da oferta de ações básicas, em uma perspectiva epidemiológica.

Dezenas dessas inovações estão vinculadas à implementação do PACS e do PSF, cujas atividades extrapolam os muros das unidades de saúde, articulando ações educativas de promoção com ações de prevenção de riscos e agravos, e ações básicas de atenção à saúde de grupos prioritários. Ainda que tenham sido elaborados originalmente como programas focalizados, dirigidos a grupos da população relativamente excluídos do acesso ao consumo de serviços, a Saúde da Família vem se apresentando, em vários municípios, como estratégia de reorganização da atenção primária da saúde, com a pretensão de influir na reestruturação do modelo de atenção em sua totalidade (MS, 2000).
Algumas iniciativas, especificamente, tratam de ir além dos aspectos técnicos e organizacionais envolvidos na prestação de serviços, introduzindo mudanças na formação e capacitação dos sujeitos das práticas e nas relações de trabalho, como é o caso das experiências que tomam como foco a melhoria da qualidade e a humanização do atendimento. De fato, os projetos voltados para a "qualidade" na medida em que introduzem o chamado "foco no cliente" e buscam modificar aspectos técnicos e organizacionais do processo de prestação de serviços, seja no âmbito ambulatorial ou hospitalar, acabam por problematizar aspectos críticos do modelo médico hegemônico, como a relação médico-paciente (em suas dimensões éticas e culturais) ou mesmo os limites dos conhecimentos e tecnologias utilizadas tão intensamente no âmbito deste modelo (Teixeira, 1997).

As propostas no sentido de organizar o chamado "acolhimento" e estabelecimento do "vínculo" dos usuários com os profissionais e os serviços, também trazem à tona a problematização da chamada “(des)humanização” do atendimento, em função da tecnificação do cuidado à saúde (Merhry, 1994). A organização de práticas de "acolhimento" à clientela dos serviços públicos de saúde, e o estabelecimento de vínculos entre profissionais e clientela, implica mudanças na "porta de entrada" dos serviços, com introdução de mudanças na recepção do usuário, no agendamento das consultas e na programação da prestação de serviços, de modo a incluir atividades derivadas na "releitura" das necessidades sociais de saúde da população (Merhy, 1994).

Além de contribuir para a humanização e melhoria da qualidade da atenção, o "acolhimento” é uma estratégia de reorientação da atenção à demanda espontânea que pode ter efeitos significativos na racionalização dos recursos, no perfil ocupacional dos profissionais e nas relações destes com os usuários, e até no estabelecimento de processos de mudança nas concepções da população acerca das suas necessidades de saúde e lugar ocupado pelo consumo de serviços de saúde na melhoria do seu bem-estar (Cecílio, 1994; Merhy \& Onocko, 1997). Nesse sentido, já vem sendo absorvido no âmbito de unidades básicas de saúde e de equipes de Saúde da Família, podendo vir a ser incorporado, em larga escala, aos processos de reorganização do atendimento nos "módulos assistenciais" previstos no processo de implementação da NOAS 2001.

Do ponto de vista organizacional e programático, não se pode deixar de fazer referência à experiência acumulada pelo núcleo de pes- 
quisa do Departamento de Medicina Preventiva da Universidade de São Paulo, que partindo da crítica à programação em saúde, propõe sua "refuncionalização" como instrumento de redefinição do processo de trabalho em saúde, com base na identificação das necessidades sociais de saúde da população que demanda os serviços das unidades básicas. Nesse sentido, a definição de "ações programáticas" se ancora no conhecimento acerca dos problemas e necessidades dos indivíduos e dos grupos da população em situações concretas, em um processo que resgata a dimensão técnico-científica e ética do trabalho em saúde. (Schraiber, 1990, 1993, 1995; Schraiber et al., 1996).

Dessa maneira, também cabe referência às propostas englobadas sob a denominação de "vigilância da saúde", que incluem o fortalecimento das ações de vigilância epidemiológica e sanitária, a implantação de ações de vigilância nutricional dirigidas a grupos de risco, a vigilância na área de saúde do trabalhador, levando em conta os ambientes de trabalho e os riscos ocupacionais, a vigilância ambiental em áreas específicas de risco epidemiológico, sem perder de vista a necessidade de reorientação das ações de prevenção de riscos e de recuperação da saúde, isto é, a própria assistência médico-ambulatorial, laboratorial e hospitalar (Mendes, 1993, 1994; Paim, 1999; Teixeira, 1994, 2000; Teixeira et al., 1998; Vilasboas, 1998; Vilasboas et al., 1995).

A incorporação da noção de vigilância da saúde ao planejamento municipal e a busca de redefinição das "ações programáticas de saúde" no âmbito das unidades básicas, nos "módulos assistenciais" e "sistemas microrregionais de saúde" previstos com a implementação da NOAS 2001, constitui uma alternativa de superação do viés economicista da Programação Pactuada Integrada (PPI), basicamente um instrumento de racionalização da oferta de serviços pelas unidades de saúde, que não problematiza o conteúdo das práticas que são realizadas nem a sua adequação às necessidades e problemas de saúde da população dos municípios.

Do mesmo modo, esta perspectiva aponta caminhos para a reorganização das ações previstas nos chamados "programas especiais", instrumentos normativos de organização das ações de saúde, definidos centralmente com base na revisão de informações clínico-epidemiológicas relativas a problemas ou a grupos específicos da população, recortados segundo idade, gênero e/ou exposição a determinados riscos no ambiente de trabalho ou no ambiente social mais amplo, cujo processo de operacionalização não leva em conta as característi- cas específicas das populações dos distintos territórios e as condições concretas de vida, que condicionam o modo de expressão dos problemas de saúde e doença (Teixeira, 2000, 2001).

O processo de organização dos "sistemas microrregionais de saúde” constituirá, sem dúvida, um espaço privilegiado de experimentação e análise dos limites e possibilidades dessas propostas, tanto no âmbito da assistência propriamente dita, que Mendes (2001) denomina "gestão da clínica" e "gestão dos pontos de atenção à saúde (atenção básica, hospitalar, sistemas de apoio), quanto na "gestão dos riscos populacionais", na perspectiva apontada pela proposta da vigilância da saúde.

Com uma visão ainda mais ampla, que extrapola os limites do sistema de serviços de saúde, coloca-se a proposta política das "cidades saudáveis” noção abrangente da gestão governamental, que inclui a promoção da cidadania e o envolvimento criativo de organizações "comunitárias” no planejamento e execução de ações intersetoriais dirigidas à melhoria das condições de vida e saúde, principalmente em áreas territoriais das grandes cidades onde se concentra a população exposta a uma grande quantidade de riscos vinculados à precariedade das condições de vida, incluindo fatores econômicos, ambientais e culturais (Ferraz, 1999; Keinert, 1997; Malik, 1997; Westphal, 1997; Xavier, 2000).

O movimento em torno das "cidades saudáveis”, originário do Canadá na década de 80 e assumido pela Organização Mundial da Saúde (OMS), vem sendo incorporado por várias administrações municipais brasileiras nos últimos anos, gerando experiências inovadoras de articulação intersetorial para o enfrentamento de problemas cujos determinantes extrapolam o âmbito de ação do sistema de serviços de saúde, contribuindo para a concretização de processos de descentralização, intersetorialidade e, principalmente, para a ampliação do leque de ações sociais voltadas para o atendimento de necessidades de saúde da população (Akerman et al., 1997; Junqueira, 1997, 1998; Ribeiro, 1997; Teixeira \& Paim, 2000).

Ainda nessa linha, cabe destacar a possibilidade de formulação de políticas públicas que tomam como fundamento a promoção da saúde, movimento político-ideológico baseado na noção de "campo da saúde" (Dever, 1988), que enfatiza ações voltadas à melhoria das condições e estilos de vida de grupos populacionais específicos, apoiando-se amplamente em atividades de Educação e Comunicação e na formulação de "políticas públicas saudáveis" nas várias esferas de governo - nacional, estadual e municipal - (Ferraz, 1993, 1998). 
Essa perspectiva vai além dos limites das “cidades saudáveis”, afetando a sociedade como um todo, podendo-se citar como exemplos, a restrição à propaganda de produtos do tabaco nos meios de comunicação de massa (controle do tabagismo), as ações de marketing sanitário na mídia (saúde na mídia), voltadas, por exemplo, para a promoção de sexo seguro (controle das doenças sexualmente transmissíveis e AIDS) ou o controle na utilização de medicamentos com estímulo ao uso dos genéricos. A abrangência dessas políticas, entretanto, vai além da promoção de "estilos de vida" que preservam a saúde ou ao controle de produtos e serviços danosos a ela, implicando o estabelecimento de uma certa "liderança" e um protagonismo das instituições de saúde (MS, SES e SMS) na reorientação das políticas econômicas e sociais em seu conjunto.

\section{Comentários finais}

Apesar da diversidade e abrangência das propostas em debate e das experiências em processo no país, pode-se considerar que nenhuma delas dá conta, sozinha, de todos os aspectos envolvidos na construção de um novo modelo de atenção à saúde, ou melhor, de modelo(s) de atenção à saúde adequados à heterogeneidade estrutural e à diversidade epidemiológica e social da população (Barreto \& Carmo, 2000).

O desafio que se coloca é o de difundir, multiplicar e institucionalizar as propostas que vêm sendo debatidas nos centros acadêmicos e sistemas de serviços em vários estados e municípios das diversas regiões do país, com apoio ou não de organizações internacionais de cooperação técnica. Desse modo, se poderia tratar de incorporá-las à prática no âmbito dos sistemas microrregionais de saúde, gerando a acumulação de experiências que apontassem para além da retórica, efeitos concretos nas práticas de saúde.

Nesse sentido, são necessários o desencadeamento e fortalecimento de ações políticas e técnico-administrativas no âmbito federal, estadual e municipal, tendo como eixo o fortalecimento do nível municipal e a organização dos sistemas microrregionais de saúde, espaços onde de pode introduzir mudanças gerenciais, organizativas e técnico-assistenciais que contribuam para a construção de modelos de atenção capazes de dar respostas adequadas aos problemas e necessidades de saúde da população de cada local.

Assim, é importante que o MS e as SES invistam no fortalecimento da sua capacidade institucional, de modo a possibilitar a realização de análises permanentes da situação de saúde e a institucionalização de processos de planejamento, programação e avaliação de ações e serviços que subsidiem a definição e revisão contínua da configuração dos sistemas microrregionais em cada estado.

No âmbito municipal e microrregional, especificamente, o desafio maior é envolver os secretários de saúde e prefeitos municipais em um movimento nacional de reorientação do modelo de atenção à saúde, que se fundamente na noção de "municípios saudáveis" e se desdobre em ações intersetoriais de promoção da saúde e melhoria de condições de vida, bem como no fortalecimento das ações de vigilância sanitária, epidemiológica e ambiental, ao lado da reorganização da atenção básica e da regulação da assistência de média e alta complexidade.

Do ponto de vista político mais geral, o desafio vai além da capacidade de mobilização do MS e das SES e SMS, devendo envolver as lideranças dos diversos partidos e as organizações da sociedade civil empenhadas na busca de alternativas ao modelo vigente. $\mathrm{O}$ momento atual, no qual começam os debates em torno das próximas eleições, é propício à ampliação dessa discussão e ao estabelecimento de compromissos que venham a se expressar na formulação de propostas de políticas sociais e de saúde a serem implementadas no âmbito nacional, estadual e local.

Esse processo, heterogêneo em função das especificidades de cada estado e região, pode recolocar o debate político da área de saúde no contexto mais geral de busca de estratégias de desenvolvimento econômico e social, que contribuam para o que Boaventura Santos denomina "globalização alternativa (...) mais justa e eqüitativa que permita uma vida digna e decente à população mundial, e não apenas a um terço dela, como acontece hoje" (Santos, 2000:3). Considerando, ademais, as complexas relações estabelecidas entre o global e o local, cabe enfatizar o envolvimento dos dirigentes, trabalhadores de saúde e a população organizada politicamente em torno das suas demandas sociais, nesse debate, enquanto uma forma continuamente renovada de construção dos sujeitos da saúde coletiva (Minayo, 2001).

Desse modo, a problematização permanente dos significados da saúde, não apenas enquanto uma área de política, um serviço, um modelo de atenção, mas sobretudo um modo de vida e um valor social, pode fazer parte do debate político e do processo de "apoderamento" (empowerment) que possibilite o desenvol- 
vimento de práticas voltadas à construção de uma "sociedade de bem-estar social" (Dreifuss, 1997), utopia tanto mais necessária quanto mais distante, em tempos de intolerância.

\section{Referências}

AKERMAN, M.; MASSEI, W.; CARBAL, S.; BROCH, A.; CREMONESE, A.; ALVES, T. S. \& FRICHENBRUDER, M. T. M., 1997. A concepção de um projeto de observatório de qualidade de vida: Relato de uma experiência realizada em Campinas-SP. Saúde e Sociedade, 6:83-99.

CAMPOS, F. E. \& BELISÁRIO, S. A., 2001. O Programa de Saúde da Família e os desafios para a formação profissional e a educação continuada. Interface, 5:133-142.

CECÍLIO, L. (org.), 1994. Inventando a Mudança na Saúde. São Paulo: Editora Hucitec.

DEVER, G. E. A., 1988. A Epidemiologia na Administração dos Serviços de Saúde. São Paulo: Pioneira.

DREIFUSS, R., 1997. A Época das Perplexidades Mundialização, Globalização e Planetarização: Novos Desafios. 2a Ed. Petrópolis: Editora Vozes.

FERRAZ, S. T., 1993. A pertinência da adoção da filosofia de cidades saudáveis no Brasil. Saúde em Debate, 41:45-49.

FERRAZ, S. T., 1998. Promoção da saúde: Viagem entre dois paradigmas. Revista de Administração Pública, 32:49-60.

FERRAZ, S. T., 1999. Cidades Saudáveis: Uma Urbanidade para 2000. Brasília: Paralelo 15.

JUNQUEIRA, L. P., 1997. Novas formas de gestão na saúde: Descentralização e intersetorialidade. Saúde e Sociedade, 6:31-46.

JUNQUEIRA, L. P., 1998. Descentralização e intersetorialidade: A construção de um modelo de gestão municipal. Revista de Administração Pública, 32:11-22.

KEINERT, T. M. M., 1997. Planejamento governamental e políticas públicas: A estratégia "Cidades Saudáveis". Saúde e Sociedade, 6:55-64.

LEVCOVITZ, E.; LIMA, L. \& MACHADO, C., 2001. Política de saúde nos anos 90: Relações intergovernamentais e o papel das Normas Operacionais Básicas. Ciência \& Saúde Coletiva, 6:269-291.

LUCCHESE, P. T. R.; CAPISTRANO FILHO, D.; PAIM, J. S.; NORONHA, J. C.; GOLDBAUM, M.; BRETAS Jr., N; PIOLA, S. F.; OLIVEIRA Jr., S. M.; VIANNA, S. M. \& BARROS, M. E. D., 2000. 11a Conferência Nacional de Saúde. Efetivando o SUS: Acesso, Qualidade e Humanização da Atenção à Saúde, com Controle Social. Termos de Referência para Desenvolvimento dos Sub-Temas. Brasília: Assessoria de Programação da 11ạ Conferência Nacional de Saúde. (mimeo.)
MALIK, A. M., 1997. Cidades saudáveis: Estratégia em aberto. Saúde e Sociedade, 6:19-30.

MENDES, E. V., 1993. A construção social da vigilância à saúde no Distrito Sanitário. In: A Vigilância à Saúde no Distrito Sanitário (E. V. Mendes, org.), Série Desenvolvimento de Serviços de Saúde 10, pp. 7-19, Brasília: Organização Pan-Americana da Saúde.

MENDES, E. V. (org.), 1994. Planejamento e Programação Local da Vigilância da Saúde no Distrito Sanitário. Série Desenvolvimento de Serviços de Saúde 13. Brasília: Organização Pan-Americana da Saúde.

MENDES, E. V., 2001. Os Grandes Dilemas do SUS. Salvador: Casa da Qualidade Editora.

MERHY, E. E., 1994. Em busca da qualidade dos serviços de saúde: Os serviços de porta aberta para a saúde e o modelo tecno-assistencial em defesa da vida. In: Inventando a Mudança na Saúde (L. Cecílio, org.), pp. 117-160, São Paulo: Editora Hucitec.

MERHY, E. E. \& ONOCKO, R. (org.), 1997. Agir em Saúde: Um Desafio para o Público. São Paulo: Editora Hucitec/Buenos Aires: Lugar Editorial.

MINAYO, M. C. S., 2001. Estrutura e sujeito, determinismo e protagonismo histórico: Uma reflexão sobre a práxis da saúde coletiva. Ciência \& Saúde Coletiva, 6:7-19.

MOLESINI, J. A. O., 1999. Municipalização da Saúde na Bahia: Estudo Exploratório da Implementação da NOB 01/93. Dissertação de Mestrado, Salvador: Instituto de Saúde Coletiva, Universidade Federal da Bahia.

MS (Ministério da Saúde), 1993. Norma Operacional Básica do Sistema Único de Saúde/NOB-SUS 96. Gestão Plena com Responsabilidade pela Saúde do Cidadão. Brasília: MS.

MS (Ministério da Saúde), 1996. Descentralização das Ações e Serviços de Saúde: A Ousadia de Fazer Cumprir a Lei. Brasília: MS.

MS (Ministério da Saúde), 2000. Avaliação da Implantação e Funcionamento do Programa de Saúde da Família - PSF. Brasília: MS.

MS (Ministério da Saúde), 2001. Regionalização da Assistência à Saúde: Aprofundando a Descentralização com Eqüidade no Acesso (Norma Operacional da Assistência à Saúde. NOAS. SUS 01/01. Portaria MS/GM no 95, de 26 de Janeiro de 2001). Brasília: MS 
PAIM, J, S., 1993. A reorganização das práticas de saúde em distritos sanitários. In: Distrito Sanitário: O Processo Social de Mudança das Práticas Sanitárias do Sistema Único de Saúde (E. V. Mendes, org.), pp. 187-220, São Paulo: Editora Hucitec/Rio de Janeiro: ABRASCO.

PAIM, J. S., 1994. A reforma sanitária e os modelos assistenciais. In: Epidemiologia \& Saúde (M. Z. Rouquayrol, org.), pp. 455-466, Rio de Janeiro: MEDSI.

PAIM, J. S., 1999. Políticas de descentralização e atenção primária à saúde. In: Epidemiologia \& Saúde (M. Z. Rouquayrol, org.), pp. 489-503, 5a Ed. Rio de Janeiro: MEDSI

PAIM, J. S., 2001. Saúde da família: Espaço de reflexão e de contra-hegemonia. Interface, 5:143-146.

RIBEIRO, R. C., 1997. A construção de um município saudável: Descentralização e intersetorialidade A experiência de Fortaleza. Saúde e Sociedade, 6:47-54.

SANTOS, B., 2000. Praga, Brasil. Folha de São Paulo, São Paulo, 2 nov. Caderno 1: Tendências/Debates, p. 3.

SCHRAIBER, L. (org.), 1990. Programação em Saúde Hoje. São Paulo: Editora Hucitec/Rio de Janeiro: ABRASCO.

SCHRAIBER, L. B., 1993. Epidemiologia em serviços: Uma tecnologia de que tipo? Informe Epidemiológico do SUS, 2:5-32.

SCHRAIBER, L. B., 1995. Políticas públicas e planejamento nas práticas de saúde. Saúde em Debate, 47:28-35.

SCHRAIBER, L. B.; NEMES, M. I. B. \& GONÇALVES, R. B., 1996. Saúde do Adulto: Programas e Ações na Unidade Básica. São Paulo: Editora Hucitec.

SILVA Jr., A., 1998. Modelos Tecno-Assistenciais em Saúde. O Debate no Campo da Saúde Coletiva. São Paulo: Editora Hucitec.

SOLLA, J. \& MENEZES, G., 2000. Municipalização plena do sistema de saúde: Construindo um sistema público e gratuito de atenção à saúde em Vitória da Conquista. Ciência \& Saúde Coletiva, 5(Sup.):171.
TEIXEIRA, C. F., 1994. A construção social do planejamento e programação local da vigilância a saúde no Distrito Sanitário. In: Planejamento e Programação Local da Vigilância da Saúde no Distrito Sanitário (E. V. Mendes, org.), Série Desenvolvimento de Serviços de Saúde 13, pp. 43-59, Brasília: Organização Pan-Americana da Saúde.

TEIXEIRA, C. F., 1997. O desafio da qualidade em saúde. Bahia. Análise \& Dados, 6:82-87.

TEIXEIRA, C. F., 2000. Modelos de atenção voltados para a qualidade, efetividade, eqüidade e necessidades prioritárias de saúde. In: Caderno da $11^{a}$ Conferência Nacional de Saúde, pp. 261-281, Brasília: Conselho Nacional de Saúde, Ministério da Saúde.

TEIXEIRA, C. F., 2001. Planejamento Municipal em Saúde. Salvador: Instituto de Saúde Coletiva, Universidade Federal da Bahia.

TEIXEIRA, C. F. \& PAIM, J. S., 2000. Planejamento e programação de ações intersetoriais para a promoção da saúde e da qualidade de vida. Revista de Administração Pública, 34:63-80.

TEIXEIRA, C. F; PAIM, J. S. \& VILASBOAS, A. L., 1998. SUS, modelos assistenciais e vigilância da saúde. Informe Epidemiológico do SUS, 7.

VILASBOAS, A. L., 1998. Vigilância à Saúde e Distritalização: A Experiência de Pau da Lima. Dissertação de Mestrado, Salvador: Instituto de Saúde Coletiva, Universidade Federal da Bahia.

VILASBOAS, A. L.; TEIXEIRA, M. G. \& TEIXEIRA, C. F., 1995. Vigilância à Saúde. Relatório da Oficina de Trabalho do III Congresso Brasileiro de Epidemiologia. Salvador: ABRASCO. (mimeo.)

WESTPHAL, M. F., 1997. Municípios saudáveis: Aspectos conceituais. Saúde e Sociedade, 6:9-18.

XAVIER, C., 2000. Cidade saudável, uma filosofia e uma idéia. Tema, 19:3-5.

Recebido em 24 de abril de 2002

Aprovado em 4 de setembro de 2002 